\title{
The Role of Dopant Concentration on Conductivity and Mobility of CdTe Thin Films
}

\author{
Ala J. Al-Douri, ${ }^{1}$ F. Y. Al-Shakily, ${ }^{2}$ Abdalla A. Alnajjar, ${ }^{1}$ and Maysoon F. A. Alias ${ }^{3}$ \\ ${ }^{1}$ Applied Physics Department, Sciences College, University of Sharjah, P.O. Box 27272, Sharjah, UAE \\ ${ }^{2}$ Physics Department, Education College, Al-Mustansirya University, Baghdad, Iraq \\ ${ }^{3}$ Physics Department, Science College, University of Baghdad, P.O. Box 47162, Jadiriyah, Baghdad, Iraq
}

Correspondence should be addressed to Ala J. Al-Douri, douri@sharjah.ac.ae

Received 16 August 2010; Revised 9 April 2011; Accepted 27 April 2011

Academic Editor: Jörg Fink

Copyright () 2011 Ala J. Al-Douri et al. This is an open access article distributed under the Creative Commons Attribution License, which permits unrestricted use, distribution, and reproduction in any medium, provided the original work is properly cited.

\begin{abstract}
Films of CdTe pure and doped with various atomic percentages of $\mathrm{Al}$ and $\mathrm{Sb}(0.5,1.5 \& 2.5)$ were prepared, and their electrical properties were investigated. The films were prepared by thermal evaporation on glass substrates at two substrate temperatures $\left(T_{s}=\mathrm{RT} \& 423 \mathrm{~K}\right)$. The results showed that the conduction phenomena of all the investigated CdTe thin films on glass substrates are caused by two distinct mechanisms. Room temperature DC conductivity increases by a factor of four for undoped CdTe thin films as $T_{s}$ increases and by 1-2 orders of magnitude with increasing dopant percentage of $\mathrm{Al}$ and $\mathrm{Sb}$. In general, films doped with $\mathrm{Sb}$ are more efficient than Al-doped films. The activation energy $\left(E_{a 2}\right)$ decreases with increasing $T_{s}$ and dopant percentage for both $\mathrm{Al}$ and $\mathrm{Sb}$. Undoped CdTe films deposited at RT are p-type convert to n-type with increasing $T_{s}$ and upon doping with $\mathrm{Al}$ at more than $0.5 \%$. The carrier concentration decreases as $T_{s}$ increases while it increases with increasing dopant percentage. Hall mobility decreases more than three times as $\mathrm{Al}$ increases whereas it increases about one order of magnitude with increasing $\mathrm{Sb}$ percentage in CdTe thin films deposited at $423 \mathrm{~K}$ and RT, respectively.
\end{abstract}

\section{Introduction}

Cadmium telluride (CdTe) is a member of the II-VI family of compound semiconductors that shows unique properties making it important and quite suitable for several applications, such as utilization in ternary alloys $(\mathrm{CdHgTe})$, and use as a buffer layer for the growth of $\mathrm{Hg}_{1-x} \mathrm{Cd}_{x} \mathrm{Te}$ (MCT) or $\mathrm{Hg}_{1-x}\left(\mathrm{Cd}_{y} \mathrm{Zn}_{1-y}\right)_{x} \mathrm{Te}$ (MCZT) for infrared detectors [1, 2]. Its band gap of $1.5 \mathrm{eV}$, just in the middle of the solar spectrum, and it processes high absorption coefficient $(\alpha)$ $\left(>10^{4} \mathrm{~cm}^{-1}\right)$ for the visible solar spectrum [3]. A $2 \mu \mathrm{m}$ thick layer of CdTe is completely opaque, while a $20 \mu \mathrm{m}$ thick layer of $\mathrm{Si}$ is required to absorb a similar radiation intensity [4]. These properties make CdTe a good candidate material for photovoltaic conversion, and accordingly several companies now commercialize CdTe-based solar cells [5]. CdTe is unique among the II-VI series of semiconducting compounds, as it exhibits both n-type and p-type conductivity, making diode technology and field effect transistors possible, and it permits the fabrication of solar cells in both homojunction and heterojunction configuration [6]. Its high average atomic number of 50, wide band gap, high resistivity, and good transport properties make it very suitable for X-ray and gamma-ray detectors $[7,8]$.

The purpose of the present work is to study the effect of the substrate temperatures and dopant percentages of $\mathrm{Al}$ and $\mathrm{Sb}$ on the electrical properties of CdTe thin films. The electrical properties, including the DC conductivity and Hall Effect, were studied in dark for undoped and doped CdTe thin films with various concentrations of $\mathrm{Al}$ and $\mathrm{Sb}(0.5,1.5 \& 2.5) \%$ deposited onto glass substrates at substrate temperatures of RT and $423 \mathrm{~K}$. The transport mechanisms in these films were determined from the measurement of the dark DC conductivity and the type, concentration, and the mobility of the carriers have been estimated from Hall Effect measurement.

\section{Experimental Procedure}

The films of CdTe are deposited by thermal evaporation around $10^{-6}$ Torr vacuum pressure. Different deposition 


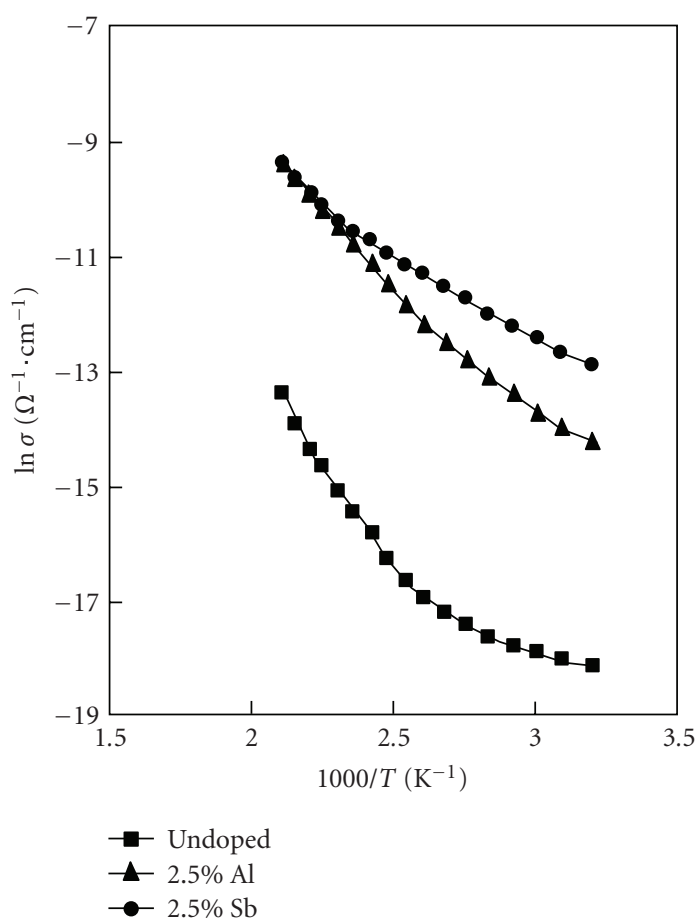

(a)

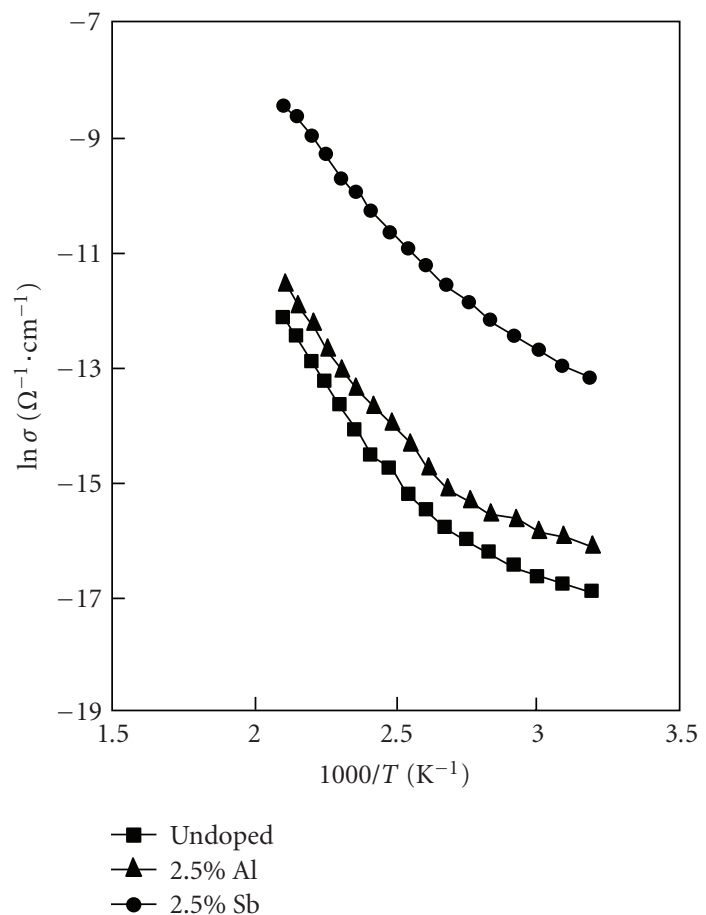

(b)

Figure 1: (a) $T_{S}=$ RT. (b) $T_{S}=423 \mathrm{~K}$.

conditions were introduced to prepare the films such as substrate temperatures $\left(T_{s}=\mathrm{RT} \& 423 \mathrm{~K}\right)$ and dopant percentages of $\mathrm{Al}$ for $\mathrm{n}$-type and $\mathrm{Sb}$ for $\mathrm{p}$-type thin film. The film thickness of about $0.5 \mu \mathrm{m}$ was grown on corning glass 7059. The composition of the prepared films was determined using energy dispersive X-ray analysis (EDX) on a Jeol JSM5600 SEM, and the EDX scan results coincide with the theoretical percentage values of $\mathrm{Cd}, \mathrm{Te}, \mathrm{Al}$, and $\mathrm{Sb}$ in undoped and doped CdTe thin films.

The electrical properties of pure and doped CdTe thin films with different percentages of $\mathrm{Al}$ and $\mathrm{Sb}$ were measured. The dark DC conductivity $(\sigma)$ for prepared films was measured as a function of substrate temperature and dopant percentages of $\mathrm{Al}$ and $\mathrm{Sb}$. Digital electrometer type Keithely 616 was used for current and voltage measurements. Hall Effect was used to find the type of film, the carrier concentration of dopant ( $\mathrm{Al} \& \mathrm{Sb})$, and mobility of carriers. For more details see [9].

\section{Results and Discussion}

3.1. DC Conductivity of CdTe Thin Films. Figures 1(a) and 1(b) show the variation of the dark DC electrical conductivity $(\sigma)$ with temperature (T) in the form of $\ln \sigma$ versus 1000/T plots for undoped and 2.5\% $\mathrm{Al}$ and $2.5 \%$ $\mathrm{Sb}$-doped CdTe thin films deposited at RT and $423 \mathrm{~K}$. The conductivity of all the investigated thin films increased with increasing temperature in the range (303-473) K. This indicates that undoped and doped CdTe films with various concentrations of both type of dopant deposited at RT and
$423 \mathrm{~K}$ have a semiconductor like behavior. On the other hand, the plots of $\ln \sigma$ versus 1000/T are nonlinear showing two clear different regions one at relatively high-temperature $(383-473) \mathrm{K}$ and the other relatively at low-temperature (303-373) K. This behavior revealed that the conduction phenomena of the investigated thin films proceed through two distinct conduction mechanisms. The plots are further analyzed to calculate the activation energies $E_{a 1}$ and $E_{a 2}$ from the slopes of the curves in both regions using equation [10]:

$$
\sigma=\sigma_{o} \exp \left\{-\frac{E_{a}}{k_{B}} T\right\}
$$

where $\sigma_{o}$ is the pre exponential factor or temperature independent conductivity, $k_{B}$ is Boltzmann constant, and $T$ is temperature.

The data shows in Figure 1, at higher temperature, the conductivity is strongly dependent on the temperature. Hence, the conduction mechanism of $E_{a 2}$ in this case is due to carriers excited beyond the mobility edges into extended states. At relatively lower temperatures, the conduction is due to carriers excited into localized states at the band edges [10].

The DC conductivity at RT $\left(\sigma_{\mathrm{RT}}\right), E_{a 1}$, and $E_{a 2}$ values for undoped and doped CdTe thin films with various concentration of $\mathrm{Al}$ and $\mathrm{Sb}(0.5,1.5 \& 2.5) \%$ deposited at RT and $423 \mathrm{~K}$ are tabulated in Table 1. It is observed that as the $T_{s}$ increased, $\sigma_{\mathrm{RT}}$ of undoped $\mathrm{CdTe}$ thin film varied from $1.3 \times 10^{-8} \Omega^{-1} \cdot \mathrm{cm}^{-1}$ to $5.1 \times 10^{-8} \Omega^{-1} \cdot \mathrm{cm}^{-1}$, that is, decrease by around a factor of four. Similar behavior was reported in literature for CdTe thin films deposited using thermal evaporation $[11,12]$ and close-spaced sublimation 
TABLE 1: Values of $\rho_{\mathrm{RT}}, \sigma_{\mathrm{RT}}, E_{a 1}$ and $E_{a 2}$ for undoped and doped CdTe thin films deposited at RT and $423 \mathrm{~K}$.

\begin{tabular}{lccccccc}
\hline CdTe thin film & $T_{s}(\mathrm{~K})$ & $\rho_{\mathrm{RT}} \times 10^{7}(\Omega \cdot \mathrm{cm})$ & $\sigma_{\mathrm{RT}} \times 10^{-6}\left(\Omega^{-1} \cdot \mathrm{cm}^{-1}\right)$ & $E_{a 1}(\mathrm{eV})$ & Temp. range $(\mathrm{K})$ & $E_{a 2}(\mathrm{eV})$ & Temp. range $(\mathrm{K})$ \\
\hline \multirow{2}{*}{ Undoped } & $\mathrm{RT}$ & 7.692 & 0.013 & 0.146 & $303-363$ & 0.612 & $363-473$ \\
& 423 & 1.961 & 0.051 & 0.189 & $303-363$ & 0.594 & $363-473$ \\
\hline Doped with & & & & & & & \\
\multirow{2}{*}{$0.5 \% \mathrm{Al}$} & $\mathrm{RT}$ & 8.333 & 0.012 & 0.255 & $303-363$ & 0.599 & $363-473$ \\
& 423 & 1.449 & 0.069 & 0.174 & $303-353$ & 0.566 & $353-473$ \\
$1.5 \% \mathrm{Al}$ & $\mathrm{RT}$ & 1.075 & 0.093 & 0.189 & $303-363$ & 0.568 & $363-473$ \\
& 423 & 1.190 & 0.084 & 0.105 & $303-343$ & 0.562 & $343-473$ \\
$2.5 \% \mathrm{Al}$ & $\mathrm{RT}$ & 0.150 & 0.668 & 0.272 & $303-353$ & 0.475 \\
& 423 & 1.064 & 0.094 & 0.154 & $303-353$ & 0.532 & $353-473$ \\
$0.5 \% \mathrm{Sb}$ & $\mathrm{RT}$ & 0.725 & 0.138 & 0.288 & $303-363$ & 0.574 & $353-473$ \\
& 423 & 1.961 & 0.051 & 0.209 & $303-363$ & 0.573 & $363-473$ \\
$1.5 \% \mathrm{Sb}$ & $\mathrm{RT}$ & 0.142 & 0.704 & 0.246 & $303-363$ & 0.519 & $363-473$ \\
& 423 & 0.252 & 0.397 & 0.175 & $303-343$ & 0.538 & $343-473$ \\
$2.5 \% \mathrm{Sb}$ & $\mathrm{RT}$ & 0.040 & 2.506 & 0.242 & $303-403$ & 0.414 & $403-473$ \\
& 423 & 0.056 & 1.796 & 0.271 & $303-363$ & 0.505 \\
\hline
\end{tabular}

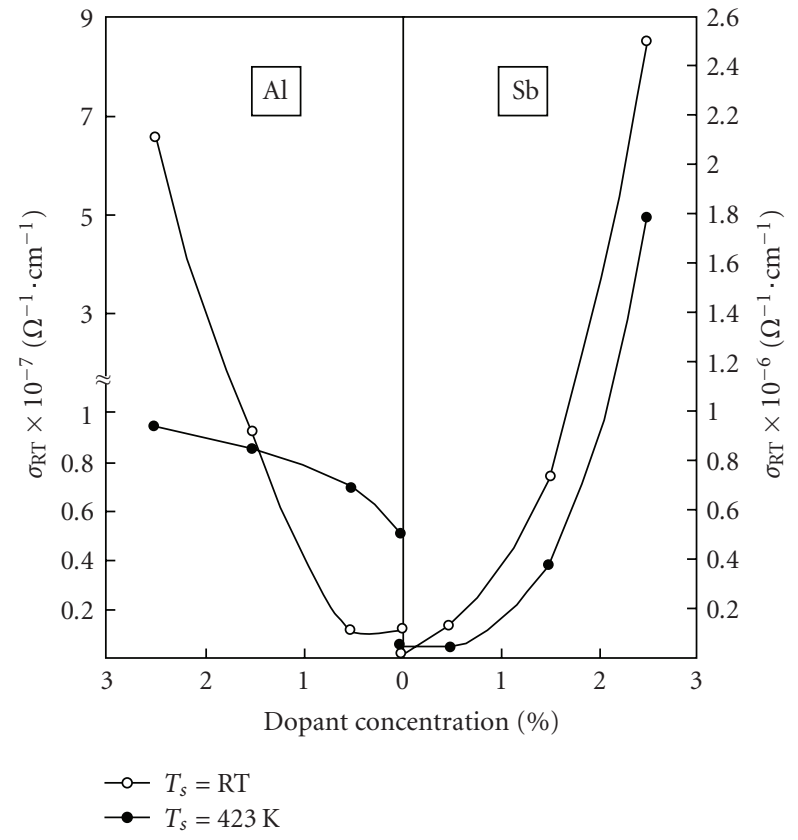

Figure 2

(CSS) techniques [13]. Lee et al. [12] suggested that the difference in conductivity found in CdTe films grown at different temperatures can be explained by the reduction of the number of grain boundaries due to the increase of the grain size. They found that the dark resistivity of CdTe films with thickness in the $2-3 \mu \mathrm{m}$ range is reduced from $6 \times 10^{7} \Omega \cdot \mathrm{cm}$ at RT to $5.4 \times 10^{6} \Omega \cdot \mathrm{cm}$ at $573 \mathrm{~K}$. Our results showed that the dark resistivity at RT for undoped CdTe is on order of $10^{7} \Omega \cdot \mathrm{cm}$. Similar outcomes were obtained by Niraula et al. [14] for undoped CdTe films grown by MOCVD with a thickness of $0.5 \mu \mathrm{m}$ at $T_{s}$ in the $423-573 \mathrm{~K}$ range. Also the same results were obtained by Rusu et al. [15] and Nory [16] for thermally evaporated CdTe thin films at RT with a thickness in the range of $0.3-0.5 \mu \mathrm{m}$ and of $0.5 \mu \mathrm{m}$, respectively. However, other researches [17-20] reported lower values than our results. This discrepancy is possibly due to the difference in the preparation techniques and in film deposition conditions.

Figure 2 shows the variation of $\sigma_{\mathrm{RT}}$ with dopant concentration of $\mathrm{Al}$ and $\mathrm{Sb}$ for CdTe thin films deposited at RT and $423 \mathrm{~K}$. It can be observed from this figure and Table 1 that, in general, $\sigma_{\mathrm{RT}}$ of CdTe films increased when such films were doped with $\mathrm{Al}$ or Sb depending on the dopant concentration. Similar behaviors were reported by Mohammed [19] for CdTe doped with Zn and Shehab [21] for CdTe doped with P.

The data tabulated in Table 1 shows that increasing the doping concentration from $0.5 \%$ to $2.5 \% \mathrm{Al}$ in CdTe films deposited at RT has caused an increase in $\sigma_{\mathrm{RT}}$ from $1.2 \times$ $10^{-8} \Omega^{-1} \cdot \mathrm{cm}^{-1}$ to $6.68 \times 10^{-7} \Omega^{-1} \cdot \mathrm{cm}^{-1}$ and a slight increase from $6.9 \times 10^{-8} \Omega^{-1} \cdot \mathrm{cm}^{-1}$ to $9.4 \times 10^{-8} \Omega^{-1} \cdot \mathrm{cm}^{-1}$ for films deposited at $423 \mathrm{~K}$. On the other hand, the $\sigma_{\mathrm{RT}}$ increases from $1.38 \times 10^{-7} \Omega^{-1} \cdot \mathrm{cm}^{-1}$ to $2.506 \times 10^{-6} \Omega^{-1} \cdot \mathrm{cm}^{-1}$ for films grown at RT and from $5.1 \times 10^{-8} \Omega^{-1} \cdot \mathrm{cm}^{-1}$ to $1.796 \times$ $10^{-6} \Omega^{-1} \cdot \mathrm{cm}^{-1}$ for film prepared at $423 \mathrm{~K}$ as the doping concentration of Sb increased from $0.5 \%$ to $2.5 \%$ in the films. These results indicated that the doping of CdTe with $2.5 \% \mathrm{Al}$ and $\mathrm{Sb}$ leads to increase in $\sigma_{\mathrm{RT}}$ by 1-2 orders of magnitude, and this is in agreement with Bayhan and Erçelebi [22]. They showed that all evaporated, undoped CdTe films deposited at $473 \mathrm{~K}$ have high resistivity $\left(\geq 10^{10} \Omega \cdot \mathrm{cm}\right)$. This value was reduced by 1-2 orders of magnitude for CdTe films doped with Sb. In general the data shown in Table 1 indicate, that $\mathrm{Sb}$ is more efficient than $\mathrm{Al}$ since $\mathrm{Sb}$ doping exhibits a higher $\sigma_{\mathrm{RT}}$ than that for $\mathrm{Al}$ doping.

Table 1 also illustrates the dependence of the activation energies $E_{a 1}$ and $E_{a 2}$ on the doping percentage of $\mathrm{Al}$ and $\mathrm{Sb}$ for CdTe thin films deposited at RT and $423 \mathrm{~K}$. From this figure and Table 1, the activation energy $E_{a 2}$ for undoped CdTe film is found to vary from $0.612 \mathrm{eV}$ to $0.594 \mathrm{eV}$ as $T_{s}$ 
TABLE 2: Values of carrier concentration and $\mu_{H}$ for undoped and doped CdTe thin films deposited at RT and $423 \mathrm{~K}$.

\begin{tabular}{|c|c|c|c|c|}
\hline CdTe thin films & $T_{s}(\mathrm{~K})$ & Carrier concentration $\times 10^{13}\left(\mathrm{~cm}^{-3}\right)$ & $\mu_{H} \times 10^{-2}\left(\mathrm{~cm}^{2} / \mathrm{V} \cdot \mathrm{s}\right)$ & Type \\
\hline \multirow{2}{*}{ Undoped } & RT & 1.107 & 0.756 & $\mathrm{P}$ \\
\hline & 423 & 0.483 & 6.599 & $\mathrm{~N}$ \\
\hline \multicolumn{5}{|l|}{ Doped with } \\
\hline \multirow{2}{*}{$0.5 \% \mathrm{Al}$} & RT & 0.172 & 4.360 & $\mathrm{P}$ \\
\hline & 423 & 0.856 & 5.052 & $\mathrm{~N}$ \\
\hline \multirow{2}{*}{$1.5 \% \mathrm{Al}$} & RT & 2.628 & 2.214 & $\mathrm{~N}$ \\
\hline & 423 & 1.151 & 4.561 & $\mathrm{~N}$ \\
\hline \multirow{2}{*}{$2.5 \% \mathrm{Al}$} & RT & 6.961 & 5.997 & $\mathrm{~N}$ \\
\hline & 423 & 3.142 & 1.869 & $\mathrm{~N}$ \\
\hline \multirow{2}{*}{$0.5 \% \mathrm{Sb}$} & RT & 3.836 & 2.248 & $\mathrm{P}$ \\
\hline & 423 & 0.397 & 8.028 & $\mathrm{P}$ \\
\hline \multirow{2}{*}{$1.5 \% \mathrm{Sb}$} & RT & 6.101 & 7.211 & $\mathrm{P}$ \\
\hline & 423 & 5.073 & 4.891 & $\mathrm{P}$ \\
\hline \multirow{2}{*}{$2.5 \% \mathrm{Sb}$} & $\mathrm{RT}$ & 13.292 & 11.783 & $\mathrm{P}$ \\
\hline & 423 & 12.566 & 8.932 & $\mathrm{P}$ \\
\hline
\end{tabular}

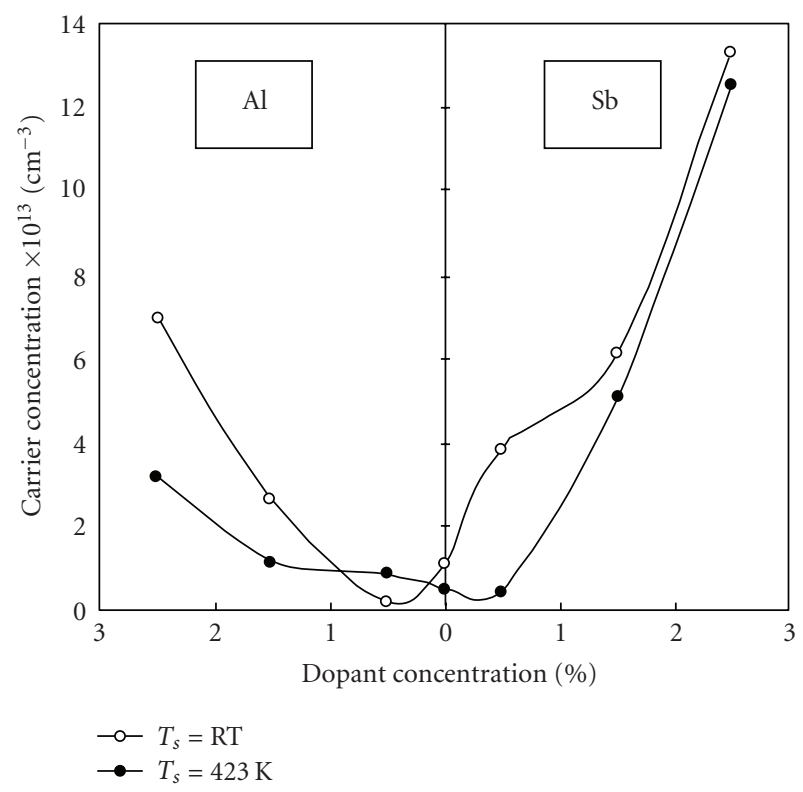

FIGURE 3

increased. This is in agreement with Al-Shadidi [23] whereas it is in contrast with Rasheed [24], who showed an increase in the activation energies with increasing substrate temperature from $300 \mathrm{~K}$ to $423 \mathrm{~K}$. A noticeable change is observed in the activation energy $E_{a 2}$ upon doping with $\mathrm{Al}$ and $\mathrm{Sb}$. The data shown in Table 1 indicate a decrease of $E_{a 2}$ from $0.599 \mathrm{eV}$ to $0.475 \mathrm{eV}$ at RT and from $0.566 \mathrm{eV}$ to $0.532 \mathrm{eV}$ at $423 \mathrm{~K}$ with increasing $\mathrm{Al}$ doping concentration from $0.5 \%$ to $2.5 \%$. The data also revealed that $E_{a 2}$ decreases from $0.574 \mathrm{eV}$ to $0.414 \mathrm{eV}$ at RT and from $0.573 \mathrm{eV}$ to $0.505 \mathrm{eV}$ at $423 \mathrm{~K}$ as the concentration of $\mathrm{Sb}$ increases from $0.5 \%$ to $2.5 \%$ in these films. The decrease in the activation energy with increasing of dopant concentration was also observed by other researchers $[19,25,26]$.
The above mentioned behavior of $E_{a 2}$ with doping concentration might be due to a decrease in the defects such as dangling bonds and vacancies as well as the creation of impurity levels within the bandgap [25]. The behavior of the activation energy $E_{a 1}$ with dopant concentrations of $\mathrm{Al}$ and $\mathrm{Sb}$ in $\mathrm{CdTe}$ thin films is not monotonic, since its value decreases then increases with increasing dopant concentration from $0.5 \%$ to $2.5 \%$ as shown in Table 1 .

3.2. Carrier Concentration and Hall Mobility. The Hall effect measurements have been used to investigate the type and concentration of charge carriers and Hall mobility $\left(\mu_{H}\right)$ for undoped, Al- and Sb-doped CdTe thin films deposited at RT and $423 \mathrm{~K}$, and the results are presented in Table 2 . As can be seen, holes were predominant in the conduction process for undoped CdTe films deposited at RT (p-type) while electrons were predominant for undoped CdTe films deposited at $423 \mathrm{~K}$ (n-type). These results are in agreement with other researchers [24, 27]. All of the CdTe thin films doped with Sb which were deposited at RT and $423 \mathrm{~K}$ were found to be ptype, whereas those doped with $\mathrm{Al}$ and deposited at RT and $423 \mathrm{~K}$ were found to be n-type except for films doped with $0.5 \% \mathrm{Al}$ at $\mathrm{RT}$ as shown in Table 2 .

Figure 3 shows the variation of carrier concentrations with different dopant concentration of $\mathrm{Al}$ and $\mathrm{Sb}$ for $\mathrm{CdTe}$ thin films deposited at RT and $423 \mathrm{~K}$. As shown in this figure and Table 2, the carrier concentration for undoped CdTe films at RT is higher than that at $423 \mathrm{~K}$. This is due to type conversion of p-type films into n-type as $T_{s}$ increased. Upon doping CdTe films with $0.5 \% \mathrm{Al}$ at $\mathrm{RT}$, the carrier concentration decreases and then increases with further increasing in $\mathrm{Al}$ doping to $2.5 \%$ due to the conversion of the films into n-type. For the corresponding films deposited at $423 \mathrm{~K}$, an increase in carrier concentration with increasing doping $(\mathrm{Al})$ from 0.0 to $2.5 \%$ is observed. The carrier concentration increases with increasing Sb dopant from 0.0 to $2.5 \%$ at RT while it decreases upon doping CdTe films with 
$0.5 \% \mathrm{Sb}$ and then increases with further increasing to $2.5 \%$ $\mathrm{Sb}$ at $423 \mathrm{~K}$.

The variation of the Hall mobility $\left(\mu_{H}\right)$ with dopant percentage of $\mathrm{Al}$ and $\mathrm{Sb}$ for CdTe thin films deposited at $\mathrm{RT}$ and $423 \mathrm{~K}$ is also shown in Table 2. One can notice from this table that $\mu_{H}$ varied in the range $(0.756-5.997)$ $\times 10^{-2} \mathrm{~cm}^{2} / \mathrm{V} \cdot \mathrm{s}$ at RT, and its value decreases more than three times from $6.599 \times 10^{-2} \mathrm{~cm}^{2} / \mathrm{V} \cdot \mathrm{s}$ to $1.869 \times 10^{-2} \mathrm{~cm}^{2} / \mathrm{V} \cdot \mathrm{s}$ at $423 \mathrm{~K}$, as the doping concentration of $\mathrm{Al}$ increased from 0.0 to $2.5 \%$, while $\mu_{H}$ increases from $0.756 \times 10^{-2} \mathrm{~cm}^{2} / \mathrm{V} \cdot \mathrm{s}$ to $11.783 \times 10^{-2} \mathrm{~cm}^{2} / \mathrm{V} \cdot \mathrm{s}$ at $\mathrm{RT}$, which is more than one order of magnitude, as the doping concentration of $\mathrm{Sb}$ increase from 0.0 to $2.5 \%$. The value of $\mu_{H}$ varies between $6.599 \times 10^{-2} \mathrm{~cm}^{2} / \mathrm{V} \cdot \mathrm{s}$ and $8.932 \times 10^{-2} \mathrm{~cm}^{2} / \mathrm{V} \cdot \mathrm{s}$ at $423 \mathrm{~K}$ with increasing $\mathrm{Sb}$ doping from 0.0 to $2.5 \%$.

Our results of the increase in $\mu_{H}$ with dopant percentage of Sb in CdTe thin films at RT is similar to that found by Huber and Lopez-Otero [27]. They noticed that for CdTe films doped with In a tendency for the mobility to decrease with decreasing carrier concentration. Also this behavior is in agreement with Al-Fwadi et al. [28] for CdSe doped with $\mathrm{Cu}$. They found that $\mu_{\mathrm{H}}$ increases exponentially with increasing $\mathrm{Cu}$ concentration which was attributed to the reduction of the scattering of the carrier from the surface as well as due to the elimination of the defects in the films and increase in crystallinity which consequently decreases the number of grain boundaries.

\section{Conclusions}

Electrical studies of CdTe thin films deposited on glass substrates using thermal evaporation and doped with various concentrations of $\mathrm{Al}$ and $\mathrm{Sb}$ indicate that:

(i) undoped CdTe thin films deposited at RT are p-type that convert to $\mathrm{n}$-type as $T_{s}$ increased and with $\mathrm{Al}$ doping of more than $0.5 \%$,

(ii) increasing dopant percentage for both $\mathrm{Al}$ and $\mathrm{Sb}$ result in an increase in the DC conductivity by $1-2$ order of magnitudes and in the carrier concentration,

(iii) increasing dopant percentage for both $\mathrm{Al}$ and $\mathrm{Sb}$ results in a decrease in the activation energy,

(iv) hall mobility decreases by more than three times as $\mathrm{Al}$ increases whereas it increases about one order of magnitude with increasing $\mathrm{Sb}$ in $\mathrm{CdTe}$ film deposited at $423 \mathrm{~K}$ and RT, respectively.

\section{References}

[1] F. Yu, "Structure of the $\mathrm{CdTe} / \mathrm{Cd}_{0.959} \mathrm{Zn}_{0.041} \mathrm{Te}, \mathrm{Hg}_{1-x} \mathrm{Cd}_{x} \mathrm{Te} /$ CdTe, CdTe/GaAs heterojunctions," Journal of Crystal Growth, vol. 205, no. 3, pp. 264-269, 1999.

[2] V. V. Bogoboyashchii, A. P. Vlasov, and I. I. Izhnin, "Mechanism for conversion of the conductivity type in arsenicdoped $\mathrm{p}-\mathrm{Cd}_{x} \mathrm{Hg}_{1-x}$ Te subject to ionic etching," Russian Physics Journal, vol. 44, no. 1, pp. 61-70, 2001.

[3] P. C. Sarmah and A. Rahman, "Current-voltage characteristics of Ag, Al, Ni-(n)CdTe junctions," Bulletin of Materials Science, vol. 24 , no. 4 , pp. $411-414,2001$.
[4] C. Polop, I. Mora-Sero, C. Munuera, J. Garcia de Andres, V. Munoz-Sanjose, and C. Ocal, "Twin coarsening in CdTe (111) films grown on GaAs (100)," Acta Materialia, vol. 54, no. 16, pp. 4285-4291, 2006.

[5] N. Armani, G. Salviati, L. Nasi, A. Bosio, S. Mazzamuto, and N. Romeo, "Role of thermal treatment on the luminescence properties of CdTe thin films for photovoltaic applications," Thin Solid Films, vol. 515, no. 15, pp. 6184-6187, 2007.

[6] S. T. Sundari, V. Swaminathan, A. K. Tyagi, and T. Mahalingam, "Microstructural studies of oxygen irradiated CdTe thin films," Physica Status Solidi (A), vol. 177, no. 2, pp. 495-502, 2000.

[7] M. Niraula, K. Yasuda, T. Ishiguro, Y. Kawauchi, H. Morishita, and Y. Agata, "Metal-organic vapor-phase epitaxy growth and characterization of thick (100) CdTe layers on (100) GaAs and (100) GaAs/Si substrates," Journal of Electronic Materials, vol. 32, no. 7, pp. 728-732, 2003.

[8] N. Lovergine, P. Prete, L. Tapfer, F. Marzo, and A. M. Mancini, "Hydrogen transport vapour growth and properties of thick CdTe epilayers for RT X-ray detector applications," Crystal Research and Technology, vol. 40, no. 10-11, pp. 1018-1022, 2005.

[9] F. Al-Shakily, Characterization of CdTe/GaAs heterojunction, Ph.D. thesis, University of Baghdad, College of Science, Baghdad, Iraq, 2009.

[10] N. F. Mott and E. A. Davis, Electronic Processes in NonCrystalline Materials, Clarendon Press, Oxford, UK, 2nd edition, 1979.

[11] P. K. Kalita, "Temperature dependence of dc photoconductivity in CdTe thin films," Pramana, vol. 60, no. 6, pp. 1247-1257, 2003.

[12] J.-H. Lee, D.-G. Lim, and J.-S. Yi, "Electrical and optical properties of CdTe films prepared by vacuum evaporation with close spacing between source and substrate," Solar Energy Materials and Solar Cells, vol. 75, no. 1-2, pp. 235-242, 2003.

[13] T. L. Chu, "Thin film cadmium telluride solar cells by two chemical vapor deposition techniques," Solar Cells, vol. 23, no. 1-2, pp. 31-48, 1988.

[14] M. Niraula, T. Aoki, Y. Nakanishi, and Y. Hatanaka, "Radical assisted metalorganic chemical vapor deposition of CdTe on GaAs and carrier transport mechanism in CdTe/n-GaAs heterojunction," Journal of Applied Physics, vol. 83, no. 5, pp. 2656-2661, 1998.

[15] G. G. Rusu, M. Rusu, E. K. Polychroniadis, and C. Lioutas, "Characterization of CdTe thin films prepared by stacked layer method," Journal of Optoelectronics and Advanced Materials, vol. 7, no. 4, pp. 1957-1964, 2005.

[16] E. M. Nory, Investigation of optical and electrical properties of Se/CdTe heterojunction, Ph.D. thesis, University of Baghdad, College of Science, Baghdad, Iraq, 2008.

[17] M. B. B. Makadsi, Preparation of CdTe/n-GaAs heterojunction detector by using flash evaporating method, Ph.D. thesis, University of Technology, Al-Rasheed College of Engineering and Science, Baghdad, Iraq, 2006.

[18] R. A. Abdulah, Study of photovoltaic characteristics of CdS/CdTe heterojunction, M.S. thesis, University of Baghdad, College of Science, Baghdad, Iraq, 2006.

[19] H. I. Mohammed, Opto-Electronic properties of CdTe: zn thin films, M.S. thesis, University of Baghdad, College of Education/ Ibn Al-Haithem, Baghdad, Iraq, 2008.

[20] G. G. Rusu, "On the electrical and optical properties of nanocrystalline CdTe thin films," Journal of Optoelectronics and Advanced Materials, vol. 3, no. 4, pp. 861-866, 2001. 
[21] A. A. M. Shehab, CdTe solar cells, M.S. thesis, University of Baghdad, College of Science, Baghdad, Iraq, 1985.

[22] H. Bayhan and Ç. Erçelebi, "Effects of post deposition treatments on vacuum evaporated CdTe thin films and CdS/CdTe heterojunction devices," Turkish Journal of Physics, vol. 22, no. 5, pp. 441-451, 1998.

[23] Z. A. Al-Shadidi, Study transport mechanism in CdTe thin film, M.S. thesis, University of Baghdad, College of Science, Baghdad, Iraq, 1995.

[24] M. A. Rasheed, Study of the effect of preparation and thickness parameters on the electrical and optical properties of (CdTe) compound, M.S. thesis, University of Baghdad, College of Science, Baghdad, Iraq, 1993.

[25] M. F. A. Alias, Optoelectronic study of a-Si-Ge-Al (As): $H$ thin films, Ph.D. thesis, University of Baghdad, College of Science, Baghdad, Iraq, 1998.

[26] N. M. Megahid, M. M. Wakkad, E. K. H. Shokr, and N. M. Abass, "Microstructure and electrical conductivity of Indoped CdS thin films," Physica B, vol. 353, no. 3-4, pp. 150$163,2004$.

[27] W. Huber and A. Lopez-Otero, "The electrical properties of CdTe films grown by hot wall epitaxy," Thin Solid Films, vol. 58, no. 1, pp. 21-27, 1979.

[28] E. Al-Fwadi, M. Alias, and F. Al-Shaikley, "The effect of $\mathrm{Cu}$ concentration on some of the electrical properties of CdSe films," Iraqi Journal of Physics, vol. 5, no. 1, pp. 63-70, 2008. 

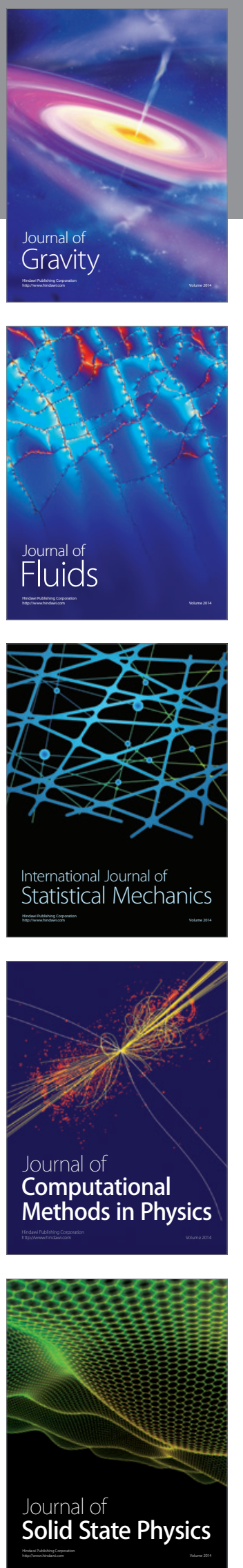

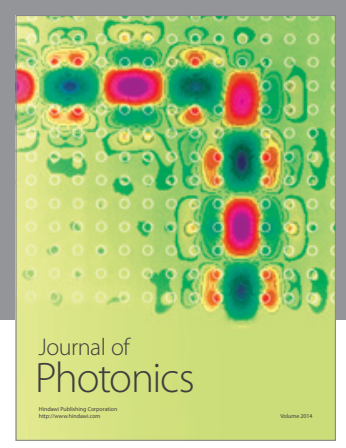

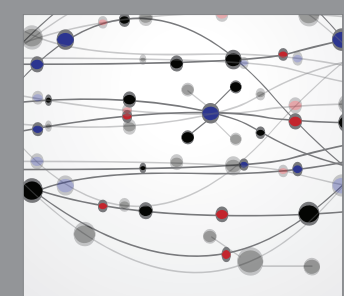

The Scientific World Journal
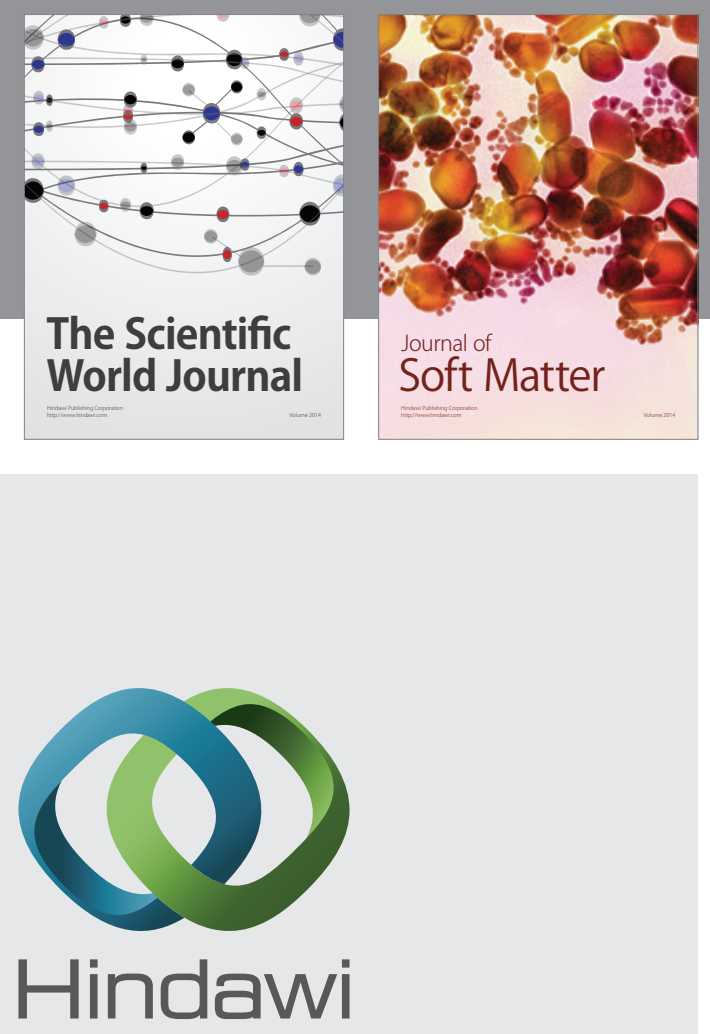

Submit your manuscripts at

http://www.hindawi.com
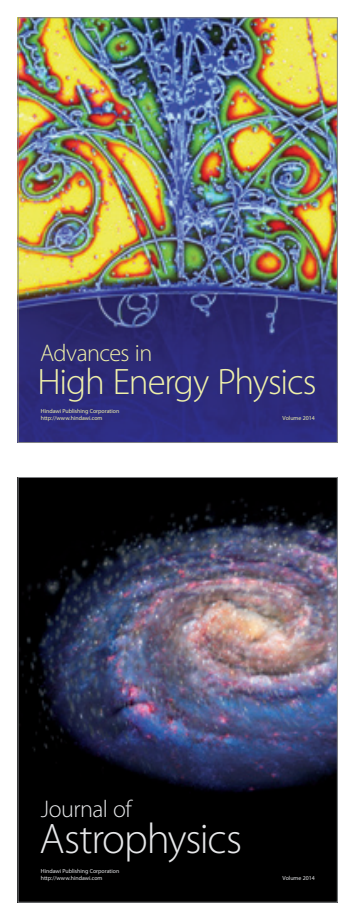
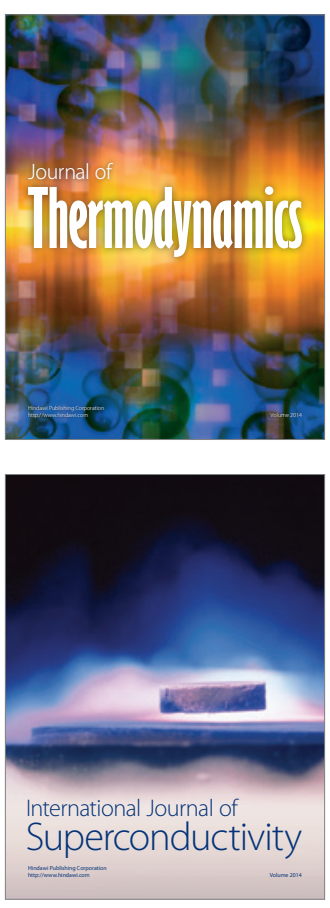
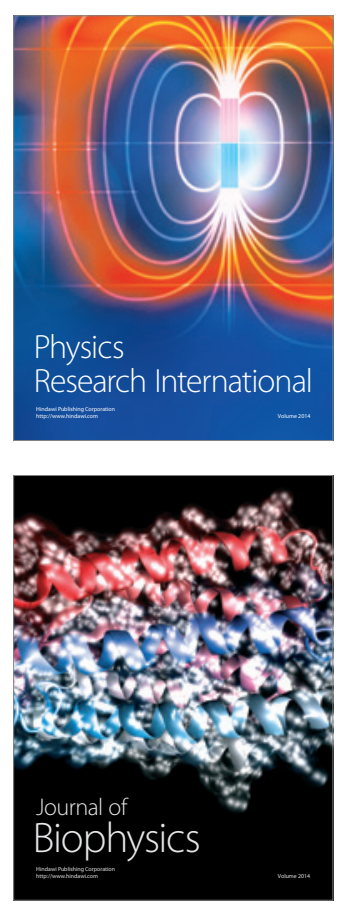
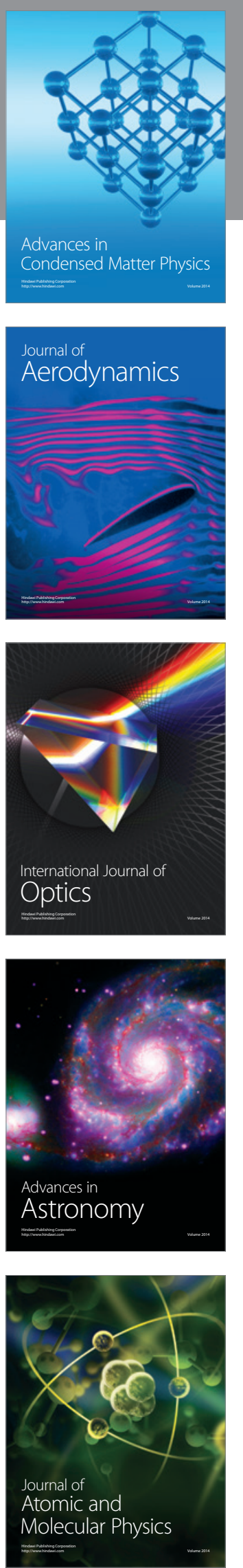